\title{
Controlling photochromic properties of molybdenum oxide based composite films by copper addition
}

\author{
Hidetoshi MIYAZAKI, ${ }^{\dagger}$ Hiroaki ICHIOKA, Hisao SUZUKI ${ }^{*}$ and Toshitaka OTA** \\ Interdisciplinary Graduate School of Science and Engineering, Shimane University, 1060 Nishikawatsu, Matsue 690-8504, Japan \\ ${ }^{*}$ Graduate School of Science and Technology, Shizuoka University, 3-5-1 Johoku, Hamamatsu 432-8561, Japan \\ ${ }^{* *}$ Ceramic Research Laboratory, Nagoya Institute of Technology, 10-6-29 Asahigaoka, Tajimi, Gifu 507-0071, Japan
}

\begin{abstract}
$\mathrm{MoO}_{3}$ based photochromic composite films were fabricated using a Mo-IPA methanol solution and a transparent urethane resin, and the photochromic property of the films was controlled by copper addition. All the composite films colored by UV-vis light irradiation, and bleached in placing a dark room. The initial color of the films changed from blue to transparent by $\mathrm{Cu}$ addition to the composite film, and $\mathrm{Cu}$ addition caused acceleration of the bleaching speed of the composite films with the $\mathrm{Cu} / \mathrm{Mo}$ ratio of higher than 0.5 .
\end{abstract}

(C2014 The Ceramic Society of Japan. All rights reserved.

Key-words : Photochromic property, Composite film, $\mathrm{MOO}_{3}, \mathrm{Copper}$

[Received August 21, 2013; Accepted October 30, 2013]

\section{Introduction}

Photochromic materials show a reversible photosensitive property by light irradiation and interception of light, and these materials are silver chloride based glasses, ${ }^{1)-3)}$ tungsten oxide based films or composites ${ }^{4-9)}$ and molybdenum oxide based film. ${ }^{10), 11)}$ The photochromic property of the $\mathrm{MoO}_{3}$ based materials appear by means of reduction of $\mathrm{Mo}^{6+}$ to $\mathrm{Mo}^{5+}$ or $\mathrm{Mo}^{4+}$ by UV-vis light irradiation, thereby the $\mathrm{MoO}_{3}$ color changes from transparent to blue or brown.

Hinokuma et al. reported fabrication of Mo-IPA using metal molybdenum powder and $\mathrm{H}_{2} \mathrm{O}_{2} .{ }^{12)}$ The resulting Mo-IPA has an empirical formula $\mathrm{MoO}_{3} \cdot \mathrm{nH}_{2} \mathrm{O}_{2} \cdot \mathrm{mH}_{2} \mathrm{O}$ where $\mathrm{n}$ and $\mathrm{m}$ depended on the extent of removing of $\mathrm{H}_{2} \mathrm{O}_{2}$ in the precursor solution. In previous, we have reported fabrication of $\mathrm{MoO}_{3}$ based photochromic composite films using an $\alpha$ - $\beta$ - and $\gamma$-peroxoisopolymolybdic acid (Mo-IPA) aqueous solution and transparent urethane resin. ${ }^{13)}$ However, in the previous investigation, ${ }^{13)}$ the color at the initial state and the bleaching speed of the composite films could not be controlled.

In this investigation, we fabricated molybdenum-based photochromic composite films using a Mo-IPA methanol solution and transparent urethane resin as starting materials, where the $\gamma$ - MoIPA was employed to fabricate composite films because of its high methanol solubility. In the present study, $\gamma$ - Mo-IPA called as "Mo-IPA. We evaluated coloring and bleaching properties of the resulting composite. Furthermore, the photochromic property of the composite films was controlled by addition of $\mathrm{CuCl}_{2}\left(\mathrm{Cu}^{2+}\right.$ ions) in the films; referring the previous investigation since existence of $\mathrm{Cu}^{2+}$ ion affected to the photochromic property of $\mathrm{WO}_{3}$ based composite films. ${ }^{9)}$

\section{Experimental procedure}

Metal molybdenum powder (particle size of $4 \mu \mathrm{m}$, Kojundo

\footnotetext{
Corresponding author: H. Miyazaki; E-mail: miya@riko.shimaneu.ac.jp

* Preface for this article: Dol http://dx.doi.org/10.2109/jcersj2.122.P1-1
}

Chemical Co. Ltd.) was used as a starting material. The molybdenum powder was dissolved completely into an ice-cooled $15 \%$ $\mathrm{H}_{2} \mathrm{O}_{2}$ solution to achieve atomic molybdenum concentration of $1.0 \mathrm{~mol} / \mathrm{L}$. After reaction, the excess $\mathrm{H}_{2} \mathrm{O}_{2}$ was removed catalytically using Pt nets for 3 days, and the $(\gamma$-) Mo-IPA solution was obtained according to the previous study. ${ }^{12)}$

Mo-IPA was dissolved into methanol with the concentration of $0.01 \mathrm{~mol} / \mathrm{L}$, and subsequently $\mathrm{CuCl}_{2}$ (Wako Pure Chemical Industries Ltd.) was dissolved into the solution with the $\mathrm{Cu}$ / Mo ratios of 0 to 1.0 . The $1.0 \mathrm{~mL}$ of the resulting $\mathrm{Cu} / \mathrm{Mo}-\mathrm{IPA}$ methanol solution was mixed into urethane resin (M-40, Asahi Kasei Chemicals Corp.) of $3.3 \mathrm{~g}$ (volume of $3 \mathrm{~cm}^{3}$ ). The mixture slurry was mixed well, and degassed at $1 \mathrm{kPa}$ for $60 \mathrm{~min}$ to expel the dissolved air in the precursor slurry. Then the precursor slurry was put between the slide glasses with film thickness of $1 \mathrm{~mm}$, and the slurry was cured by UV-Vis light irradiation for $1 \mathrm{~min}$ using a $1 \mathrm{~kW}$ low-pressure $\mathrm{Hg}$ lamp. The resulting films were colored because of the UV-vis light irradiation. Therefore, the composite film was put into a dark room to clarify the film for 7 days.

The photochromic properties of the films were evaluated at room temperature using a UV-Vis spectrophotometer (UV-1600; Shimadzu Corp., Japan). Through the investigation, a $1 \mathrm{~kW}$ lowpressure Hg lamp was used for coloration of the composite films.

\section{Results and discussion}

Composite films were fabricated using a $\mathrm{Cu} / \mathrm{Mo}$-IPA ethanol solution and a urethane resin. Figure 1 depicts the coloring property of the composite films with various $\mathrm{Cu}$ contents before and after UV-vis irradiation, and the inset photographs are the films on the paper before and after $20 \mathrm{~min} U \mathrm{UV}$-vis irradiation.

The $\mathrm{Cu}$ un-doped film before UV-vis irradiation indicated light blue color and a broad absorption at the peaks of 630 and $790 \mathrm{~nm}$. The absorption was attributed to be existence of $\mathrm{Mo}^{5+} .{ }^{10), 11), 13)}$ The $\mathrm{Cu}$ un-doped composite film after UV-vis irradiation showed broad absorption at the absorption peaks of 450 and $790 \mathrm{~nm}$, and the color of those was brown. In this study, Mo-IPA methanol solution was used as the starting material. 

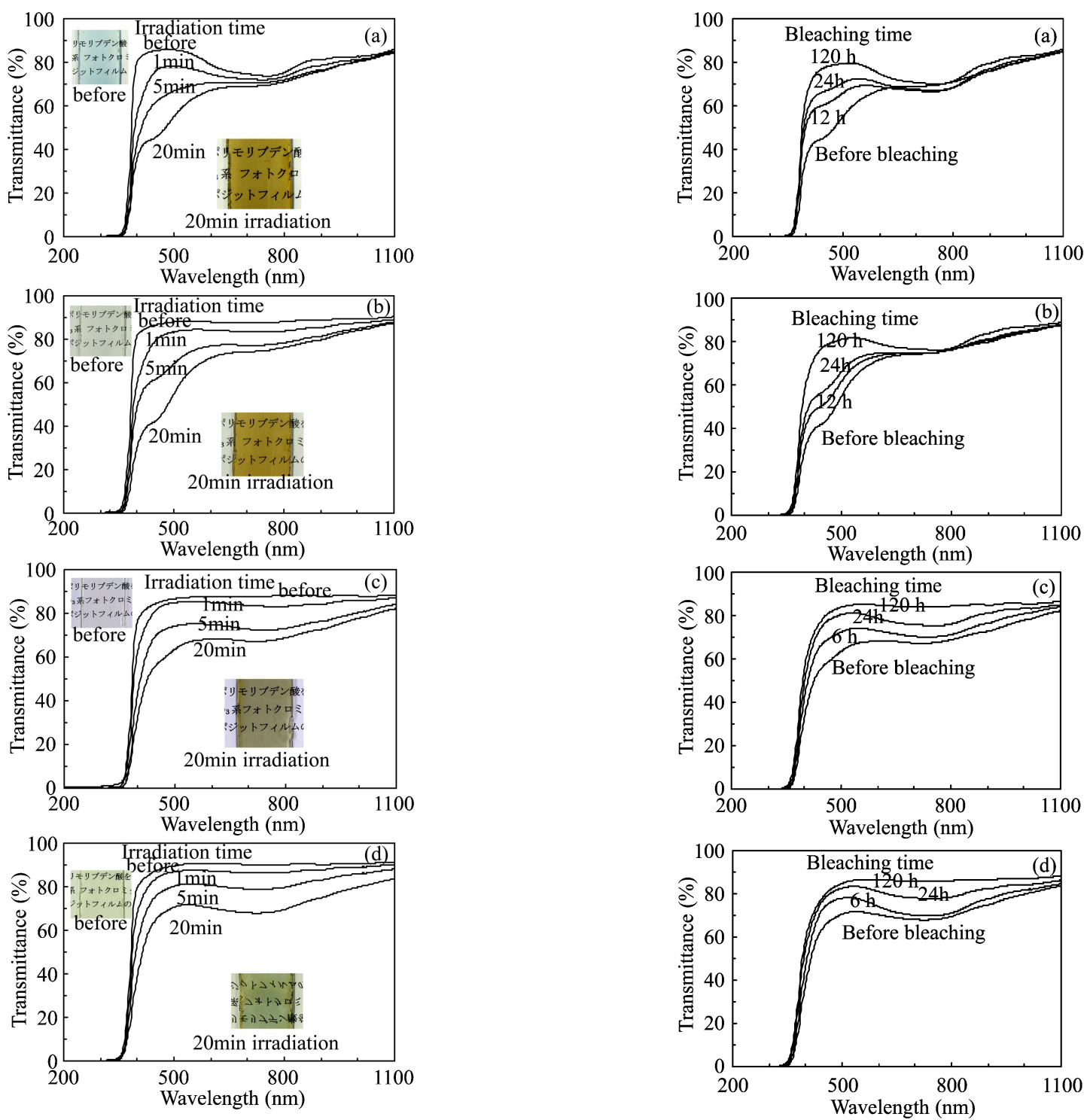

Fig. 1. Transmittance spectra for composite films with the $\mathrm{Cu} / \mathrm{Mo}$ ratios of (a) 0 , (b) 0.1 , (c) 0.5 and (d) 1.0 before and after UV-vis light irradiation. Inset photographs in respective graphs show films before and after $20 \mathrm{~min}$ UV-vis irradiation.

Electrons were released from the $\mathrm{OH}$ group or $\mathrm{MeOH}$ in the composites by UV/Vis light irradiation. $\mathrm{Mo}^{6+}$ and $\mathrm{Mo}^{5+}$ in the films were received electrons and reduced to $\mathrm{Mo}^{5+}$ and $\mathrm{Mo}^{4+}$ by $\mathrm{UV} /$ Vis irradiation, and it assumed that the color of the resulting film became brown. These photo-chemical reaction is describes as follows:

$$
\begin{aligned}
& \mathrm{Mo}^{6+}+\mathrm{e}^{-} \stackrel{\mathrm{UV}}{\stackrel{\mathrm{UV}-\text { cut }}{\longleftrightarrow}} \mathrm{Mo}^{5+} \text { (blue) }, \\
& \mathrm{Mo}^{5+}+\mathrm{e}^{-} \stackrel{\mathrm{UV}}{\stackrel{\mathrm{UV} \text {-cut }}{\longleftarrow}} \mathrm{Mo}^{4+} \text { (brown) } .
\end{aligned}
$$

The composite films with $\mathrm{Cu}$ addition were transparent at the initial state, and the no absorption peaks were observed. Where, additive of $\mathrm{Cu}$ assumed to exist as $\mathrm{Cu}^{+}$or $\mathrm{Cu}^{2+}$ ion in the composite. The $\mathrm{Cu}$ addition effect on controlling of the color of the composite films was described on the later. After UV-vis irradiation, the composite films showed the broad absorption at the peaks of $450 \mathrm{~nm}$ and around $700-800 \mathrm{~nm}$, and the color of the

composite films became brown.
In general, the color of $\mathrm{MoO}_{3}$ based photochromic films was transparent at initial state, and changed from transparent to blue according to reduce of $\mathrm{Mo}^{6+}$ to $\mathrm{Mo}^{5+}$ by Uv-vis irradiation. ${ }^{10), 11)}$ Where, the composite film (at the initial state) was put into a dark room to clarify the film for 7 days. On the contrary, the results in the present work were different from the previous investigations. The results of the present work assumed to originate from $\mathrm{Mo}^{4+}$ or interaction with the resin polymer, but further investigations are required to explain this phenomenon.

Using the optical property of the composite films, the reaction rate constant $k$ was estimated at the wavelength of $450 \mathrm{~nm}$ : the remarkable absorption peak of the films in the coloring condition. The method of calculating the photochromic reaction rate constant was described an earlier reports. ${ }^{9), 13)}$ The reaction rate equation is described as

$$
-\ln \left([A] /\left[A_{0}\right]\right)=k t,
$$

where $A_{0}$ is the initial absorbance, $t$ is the passing time and $A$ is 
the absorbance at the time $t$ passed. The calculated reaction rate constants of the composite films with the $\mathrm{Cu} / \mathrm{Mo}$ ratio of $0,0.1$ 0.5 and 1.0 were $0.122,0.148,0.105$ and $0.0354 \mathrm{~min}^{-1}$, respectively. The rate constants were very close to each other with less than the $\mathrm{Cu} / \mathrm{Mo}$ ratio of 0.5 , and that with $\mathrm{Cu} / \mathrm{Mo}$ ratio of 1.0 was slower than that of the $\mathrm{Cu}$ un-doped film. The results suggested that $\mathrm{Cu}^{2+}$ ions did not affect as a coloring sensitizer.

A bleaching property of the films was evaluated in dark room at room temperature, and Fig. 2 presents the bleaching property of the films after $20 \mathrm{~min} \mathrm{UV}$-vis irradiation. For the $\mathrm{Cu}$ un-doped composite film and the composite film with the $\mathrm{Cu} / \mathrm{Mo}$ ratio of 0.1 , the color of the films did not return completely to the initial state color. On the other hand, the color of the composite films with the $\mathrm{Cu} / \mathrm{Mo}$ ratio of 0.5 and 1.0 became to the initial state color for $120 \mathrm{~h}$.

Bleaching property of all the films was observed, and the bleaching speed was much slower than the coloring speed. Regarding the bleaching property, plots of the reactions on the Eq. (3) showed no linear property. The bleaching reaction therefore was not first-order, and the rate-determining-stage was two or more steps. The rate-control factors assumed to be electron mobility in $\mathrm{MoO}_{3}$ clusters, returning electrons from $\mathrm{Mo}^{4+}$ to matrix (hydroxyl function), and so on. Thus, the reaction constant of the films on the bleaching could not be evaluated.

To compare the bleaching speeds of the films semi-quantitatively, we calculated the half-life period of the films $\tau(\mathrm{h})$, where $\tau$ was the time taken from the transmittance of the sufficiently coloring state ( 20 min UV-vis irradiation) to the transmittance at $450 \mathrm{~nm}$ of the on a half of its after $120 \mathrm{~h}$. The calculated half-life periods $\tau$ of the films with $\mathrm{Cu} / \mathrm{Mo}$ ratios of $0,0.1,0.5$ and 1.0 were $21.8,29.2,9.7$ and $4.8 \mathrm{~h}$, respectively. The results suggested that $\mathrm{CuCl}_{2}$ addition with higher than $\mathrm{Cu} / \mathrm{Mo}$ ratio of 0.5 caused acceleration of beaching speed of the $\mathrm{MoO}_{3}$ composite films.

In previous investigations, the bleaching speed of the $\mathrm{AgCl}$ and the $\mathrm{WO}_{3}$ photochromic composite films was accelerated by $\mathrm{CuCl}_{2}$ addition. ${ }^{3), 9)}$ For the $\mathrm{MoO}_{3}$ based composite films, $\mathrm{Cu}^{2+}$ ion also acted as sensitizer on the bleaching of the composite films as follows:

$$
\begin{aligned}
& \mathrm{Mo}^{6+}+\mathrm{Cu}^{+} \underset{\mathrm{UV}-\mathrm{cut}}{\stackrel{\mathrm{UV}}{\rightleftarrows}} \mathrm{Mo}^{5+}+\mathrm{Cu}^{2+} \\
& \mathrm{Mo}^{5+}+\mathrm{Cu}^{+} \stackrel{\mathrm{UV}}{\stackrel{\mathrm{UV} \text {-cut }}{\longleftarrow}} \mathrm{Mo}^{4+}+\mathrm{Cu}^{2+} .
\end{aligned}
$$

The composite films were placed in the dark room, the equilibrium of these Eqs. (4) and (5) move to the left side. Mo in the composite films was more oxidized by existence of $\mathrm{Cu}^{2+}$ ions, thereby it assumed that the bleaching speed was accelerated. As well as this speculation, the composite films without $\mathrm{CuCl}_{2}$ addition was color because of low molybdenum valence, and the composite films with $\mathrm{CuCl}_{2}$ addition was transparent because molybdenum kept a high molybdenum valence by existence of $\mathrm{Cu}^{2+}$ ions.

\section{Conclusion}

The $\mathrm{MoO}_{3}$ based photochromic composite films were fabricated using Mo-IPA methanol solution and transparent urethane resin, and the $\mathrm{Cu}$ addition effect on the photochromic property of the films was evaluated. The initial color of the composite films could be controlled by cupper addition in the films, and the color of the composite changed from blue to transparent with increase of the $\mathrm{Cu}$ contents in the composites. Furthermore, the bleaching speed of the composite films accelerated by $\mathrm{Cu}^{2+}$ ion addition with the $\mathrm{Cu} / \mathrm{Mo}$ ratio of higher than 0.5 . These results suggested that the initial state color and the bleaching property of the $\mathrm{MoO}_{3}$ based composite films could be effectively controlled by $\mathrm{Cu}^{2+}$ ion addition.

\section{References}

1) W. H. Armistead and S. D. Stookey, Science, 144, 150-154 (1964).

2) H. Miyazaki, H. Shimoguchi, H. Suzuki and T. Ota, $A d v$. Mater. Sci. Eng., 2012, 784202 (2012).

3) H. Miyazaki, H. Shimoguchi, H. Nakayama, H. Suzuki and T. Ota, Adv. Mater. Sci. Eng., 854928 (2013).

4) Y. Shigesato, Jpn. J. Appl. Phys., 30, 1457 (1991).

5) Y. A. Yang, Y. W. Cao, P. Chen, B. H. Loo and J. N. Yao, J. Phys. Chem. Solids, 59, 1667-1670 (1998).

6) C. Bechinger, M. S. Burdis and J.-G. Zhang, Solid State Commun., 101, 753-756 (1997).

7) N. Xu, M. Sun, Y. W. Cao, J. N. Yao and E. G. Wang, Appl. Surf. Sci., 157, 81-84 (2000).

8) H. Miyazaki, Y. Baba, M. Inada, A. Nose, H. Suzuki and T. Ota, Bull. Chem. Soc. Jpn., 84, 1390-1392 (2011).

9) H. Miyazaki, M. Inada, H. Suzuki and T. Ota, Bull. Chem. Soc. Jpn., 85, 1053-1056 (2012).

10) K. Ajito, L. A. Nagahara, D. A. Tryk, K. Hashimoto and A. Fujishima, J. Phys. Chem., 99, 16383-16388 (1995).

11) J. Scarminio, A. Loureno and A. Gorenstein, Thin Solid Films, 302, 66-70 (1997).

12) K. Hinokuma, K. Ogasawara, A. Kishimoto, S. Takano and T. Kudo, Solid State Ionics, 53-56, 507-512 (1992).

13) H. Miyazaki, H. Ichioka, H. Suzuki and T. Ota, Bull. Chem. Soc. Jpn., Accepted. 